\title{
A STUDY ON NALIDIXIC ACID RESISTANT SALMONELLA AMONG THE PATIENTS ATTENDING SHREE BIRENDRA HOSPITAL
}

\author{
Raina Chaudhary ${ }^{1}$, Khagendra Sijapati ${ }^{1}$, Sunil Kumar Singh ${ }^{1}$ \\ ${ }^{1}$ Department of Pathology, Microbiology Unit, Shree Birendra Hospital
}

\begin{abstract}
Introduction: Enteric fever is the commonest public health problem in developing countries like Nepal. Multi Drug Resistant Salmonella isolates are in vitro susceptible to Quinolone but exhibited a higher Minimum Inhibitory Concentration in vivo. Such phenomenon can be demonstrated by simple disc diffusion test of Nalidixic Acid which shows resistance. This study is conducted to determine prevalence of Nalidixic Acid Resistant Salmonella with their antibiotic sensitivity pattern at Shree Birendra Hospital, Chauni, kathmandu.
\end{abstract}

Method: Of total 3945 blood samples from the patients suspected to have enteric fever were collected during the period of January 2011 to August 2011. Then it was mixed with Brain Heart Infusion , further processed according to standard methodology and their antimicrobial susceptibility was performed by Kirby-Bauer disc diffusion method.

Results: From 3945 samples, 280 (7.09\%) showed positive growth, 114 (40.7\%) Salmonella enterica serotype Typhi and 166 (59.2\%) Salmonella enterica serotype Paratyphi A. a total of 221 (78.92\%) were Nalidixic Acid Resistant Salmonella, all these strains were sensitive to Ciprofloxcin and Ofloxacin in disc diffusion test.

Conclusion: Study showed a higher frequency of Nalidixic Acid Resistant Salmonella among the patients. screening of Nalidixic Acid disc diffusion test must be done as routine work for determination of low level resistance of Quinolone so as to decide the drug for the treatment of enteric fever.

Key words: Enteric fever, Minimum Inhibitory Concentration, Multi Drug Resistant, Nalidixic Acid Resistant Salmonella, Quinolone.

\section{INTRODUCTION}

Enteric fever (Typhiod fever and Paratyphoid fever) remains an important public health in developing countries. In the recent study, it was estimated that over 2.16 million episodes of typhoid occurred worldwide, resulting in 216000 deaths and that more than $90 \%$ of this morbidity and mortality in Asia. ${ }^{2}$
Since the isolation of multidrug-resistant(MDR) strains which show resistance to all first-line antibiotics(chloramphenicol, ampicillin and trimethoprimsulfamethoxazole) in late 1980s, the fluoroquinolone class of antibiotics has beome the treatment of choice for enteric fever ${ }^{3,4}$. Fluoroquinolones have good in vitro and clinical activity against Salmonella species and are often treatment of choice in cases of life-threatening Salmonellosis due to multi-drug resistant strains ${ }^{5}$.

Correspondence:

Maj. Dr. Raina Chaudhary

Department of Pathology, Microbiology Unit. Shree Birendra Hospital.

E-mail: raina_chaudhary@yahoo.co.in

Cell No.: 9841334004 
In the recent years, several treatment failures with fluoroquinolones have also been reported due to decreased susceptibility to Ciprofloxacin ${ }^{6,7}$. Such isolates appear susceptibility with routine disc diffusion tests. Therefore, routine application of these tests for such strains is not convenient and the literature suggests the resistance to Nalidixic Acid may be an indicator of decreased susceptibility to Ciprofloxacin 6, 8,9,10.

Enteric fever caused by Nalidixic Acid resistant (NAR) isolates in endemic zone is associated with higher rate of morbidity and mortality particularly prolonged fever clearance time and increased need for retreatment of fever patients ${ }^{8}$.

Therefore, this study was conducted retrospectively to find out the prevalence of the Nalidixic Acid resistant Salmonella at Shree Birendra Hospital, Chauni.

\section{METHOD}

This study was conducted at Shree Birendra Hospital, from January 2011 to August 2011. Total of 3945 blood sample were collected from the patients suspected of enteric fever. About five milliliter of blood was collected aseptically and was mixed with Brain Heart Infusion. It was then processed according to standard methodology ${ }^{11}$. Serotyping of S.enterica was done using polyvalent O-antisera A-G and individual $\mathrm{O}$ and $\mathrm{H}$-antisera (Denka Seiken, Japan).

Antimicrobial susceptibility tests for S.typhi and S.paratyphi A were performed by Kirby-Bauer disk diffusion method following clinical and laboratory standard institute (CLSI) guideline ${ }^{12}$. Antibiotics used for susceptibility were Amoxicillin, Azithromycin, Co-trimoxazole, Chloramphenicol, Cefotaxime, Ciprofloxacin, Ofloxacin and Nalidixic Acid.

\section{RESULTS}

A total of 3945 blood samples of suspected case of enteric fever were collected. Out of these only 280 (7.09\%) samples showed positive for bacterial growth. Among the growth positive cases, 114 (40.7\%) were S.enterica serotype Typhi and remaining 166 (59.2\%) were S.enterica

Table: 1 Sensitivity pattern of Salmonella enterica

\begin{tabular}{|c|l|c|c|}
\hline S.No & Name of Antibiotics & Sensitive & Resistant \\
\hline 1. & Amoxicillin & $258(92.14 \%)$ & $22(7.8 \%)$ \\
\hline 2. & Azithromycin & $274(97.85 \%)$ & $6(2.14 \%)$ \\
\hline 3. & Chloramphenicol & $263(93.92 \%)$ & $17(6.07 \%)$ \\
\hline 4. & Co-trimoxazole & $274(97.85 \%)$ & $6(2.14 \%)$ \\
\hline 5. & Cefotaxime & $270(96.42 \%)$ & $10(3.57 \%)$ \\
\hline 6. & Ciprofloxacin & $280(100 \%)$ & - \\
\hline 7. & Nalidixic Acid & $59(21.07 \%)$ & $221(78.92 \%)$ \\
\hline 8. & Ofloxacin & $280(100 \%)$ & - \\
\hline
\end{tabular}

serotype Paratyphi A. 221(78.92\%) were NARS isolates which included both S.typhi and S.paratyphi A. Fifty four percent of S.typhi and $95.78 \%$ S.paratyphi A were NARS.

\section{DISCUSSION}

The main causes of resistance to quinolones in Gram-negative bacteria are mutation in the genes coding for DNA gyrase (gyrA and gyrB) and topoisomerase IV (parC and parE $)^{13}$. Target protection mediated by the Qnr protein and decreased accumulation of antibiotic due to a lower outer membrane permeability has also been considered as mechanism of resistance ${ }^{14}$. Giraud et.al postulated that the enhanced active efflux and early overproduction of the AcrApump in isolates with the gyrA mutation could be responsible for the decreased in susceptibility to fluoroquinolone ${ }^{15}$. It has been suggested that a low level of resistance to ciprofloxacin, probably due to point mutation in the gyrA gene, may not be detected by in vitro susceptibility tests using the current MIC breakpoints for ciprofloxacin. Therefore, in vitro resistance to Nalidixic Acid can be used to detect this low level resistance ${ }^{16}$.

The prolonged defervescence or treatment failure in typhoid fever associated with ciprofloxacin, ofloxacin or other fluoroquinolone therapy have been reported from many countries ${ }^{17}$. It has been noted that NARS strains were found to have treatment failure rate upto $36 \%$ and prolonged fecal carriage when treated with Ofloxacin ${ }^{18}$.

The present study showed total of $78.92 \%$ NARS strain which was in accordance to study done by Khanal B et.al ${ }^{19}$ during 2000-2004 in B.P.Koirala Institute of Health Science (BPKIHS) which showed $76 \%$ NARS. But it was a bit higher than the different study in Kathmandu Amatya NM et.al ${ }^{20}$ in 2005 from Model Hospital reported 62.5\% NARS similarly Mishra S et al ${ }^{18}$ study during 2007-2008 from Medicare Hospital reported 70\% NARS likewise Dahal R et $\mathrm{al}^{21}$ in 2009 from Tribhuban University Teaching Hoapital (TUTH) reported $59.5 \%$ NARS. Interestingly, all of the NARS strains were susceptible to Ciprofloxacin and Ofloxacin in disc diffusion test.

Nepal is endemic zone for enteric fever and having a series of epidemic over the last decades with changing resistance pattern. The first report of MDR S.enterica serotype Typhi in Nepal was published in 1991. In the following years, with the introduction of fluoroquinolones in the treatment, Nalidixic-Acid resistant strains associated with reduced susceptibility to Fluoroquinolones have been continuously reported from Nepal and trend of resistance is increasing ${ }^{22}$. Present study also showed that pattern of resistance is changing even in the same region.

\section{CONCLUSION}

Sensitivity pattern of the Salmonella isolates are ever changing. Nowadays fluoroquinolone group of drugs have 
been used as empiric therapy for the enteric fever at the sametime reduced level of resistance to fluoroquinolone is as emerging problem. Fortunately, which can be detected simply by Nalidixic Acid disc diffusion method. Therefore, screening for such strains by Nalidixic Acid disc diffusion must be incorporated in routine laboratory procedure. This will help for early diagnosis of low level resistance to fluoroquinolone so as to think for another therapeutic options.

\section{ACKNOWLEDGEMENT}

Authors are highly grateful to all the staff member of Microbiology Unit of Shree Birendra Hospital, Chauni for their co-operation to conduct this study.

\section{REFERENCES}

1. Neupane GP, Kim DM, Kim SH and Lee BK. In Vitro Synergism of Ciprofloxacin and Cefotaxime against Nalidixic Acid-Resistant Salmonella enterica serotype Paratyphi A and Paratyphi B. Antimicrob Agents Chemother 2011; 54(9): 3696-701.

2. Crump JA, Luby SP, Mintz ED. The global burden of typhoid fever. Bull World Health Organ 2004; 82: 345-53.

3. Lakshmi V, Ashok R, Susmita J, Shailaja VV. Changing trends in the antibiograms of Salmonella isolates at a Tertiary care hospitalin Hyderbad. Ind J Med Microb 2004; 24 (1): 45-8.

4. Chau T, Campbell JI, Galindo CM, et al. Antimicrobial drug resistance of Salmonella enterica serovar Typhi in Asia and molecular mechanism of reduced susceptibility to the fluoroquinolones. Antimicrob Agents Chemother 2007; 51: 431523. DOI: 10. 1128/AAC.00294-07.

5. Miller SI, Hohmann EL and Pegues DA. (1995) Salmonella. In Mendell, Douglas and Bennett's. Principle and Practice of Infectious Diseases, $4^{\text {th }}$ edn, 2013-33. Edited by Mandell GL, Bennett E \& Dolin R. New York. Churchill Livingstone.

6. Asna SM, Haq JA and Rahman M. Nalidixic acid resistant Salmonella enterica serovar Typhi with decreased susceptibility to ciprofloxacin caused treatment failure: a report from Bangladesh.Jpn J Infect Dis 2003; 56: 32-3.

7. Threfall EJ and Ward LR. Decreased susceptibility to ciprofloxacin in Salmonella enterica serotype Typhi in United Kingdom.Emerg Infect Dis 2001; 7: 448-50.

8. Le Lostec Z, Fegueux S, Jouve P, Cheron M, Mornet P and Boisivon A. Reduced susceptibility to quinolones in Salmonella typhi acquired in Europe: a clinical failure of treatment. Clin Microbiol Infect 1997; 3: 576-7.

9. Hakanen A, Kotilainen P, Jalava J, Silitonen A and Huovienen P. Detection of decreased fluoroquinolone susceptibility in Salmonella and validation of nalidixic acid screening test. J
Clin Microbiol 1999; 37: 3572-7.

10. Kapil AR and Das B. Nalidixic acid susceptibility test to screen ciprofloxacin resistance in Salmonella typhi. Ind J Med Res 2002; 115: 49-54.

11. Henry D. Isenberg. Clinical Microbiology Procedures Handbook. $2^{\text {nd }}$ ed. Washington D.C.: ASM press 2004.

12. Clinical and Laboratory Standards Institute. Performance standards for antimicrobial susceptibility testing, $17^{\text {th }}$ informational supplement. Wayne, PA: CLSI; M100-S17.

13. Eaves DJ, L Randall, DT Gray, A Buckey, MJ Woodward, WP Wgite and LJV Piddock. Prevalence of mutations within the quinolone resistance determining region of gyrA, gyr B , Par $\mathrm{C}$ and ParE and association with antibiotic resistance in quinolone resistant Salmonella enterica. Antimicrob Agents Chemother 2004; 48: 4012-15.

14. Jacoby GA. Mechanism of resistance to quinolones. Clin Infect Dis 2005; 41: S20-S126.

15. Giraud E, A Cloeckaert, D Kerboeuf and E Chaslus-Dancla. Evidence for active efflux as the primary mechanism of resistance to ciprofloxacin in Salmonella enterica serovar Typhimurium.Antimicrob Agents Chemother 2000; 44: 1223-8.

16. Pokharel BM, Koirala J, Dahal R, Mishra SK, Khadga PK, Tuladhar NR. Multidrug-resistant and extended-spectrum betalactamase (ESBL)-producing Salmonella enterica (serotypes Typhi and Paratyphi A) from blood isolates in Nepal: Surveillance of resistance and a search for newer alternatives. Int J Inf Dis 2006; 10: 434-8.

17. Chinh NT, Parry CM, Ly NT, et al. A randomized controlled comparision of azithromycin and ofloxacin for treatment of multidrug-resistant or nalidixic acid-resistant enteric fever. Antimicrob Agents Chemother 2000; 44: 1855-9.

18. Mishra SK, Sah JP, Shrestha R and Lakhey M. Emergence of Nalidixic acid resistant Salmonella: A confounding scene in antibiotic armamentarium. J Nep Assoc Med Lab Sci 2008; 8: 61-4.

19. Khanal B, Sharma Sk, Bhattacharya SK, Bhattarai NR, Deb m, Kanungo R. Antimocrobial susceptibility pattern of Salmonella enterica serotype Typhi in eastern Nepal. J Health Popul Nutr 2007; 25: 82-7.

20. Amatya NM, Shrestha B, Lakhak B. Etiology Agents of Bacteraemia and Antibiotic Susceptibility Pattern in Kathmandu Model Hospital. J Nep Med Assoc 2007; 46 (167); 112-8.

21. Dahal RK, Awal BK, Yadav J, Kattel HP, Banjade N, Rijal BP, Pokhrel BM. Emergence of Multidrug-Resistant and Nalidixic acid resistant Salmonella enterica isolated form blood of suspected enteric fever patients visiting Tribhuvan University teaching Hospital, Kathmandu, Nepal. Research Conference on Health Science, IOM March2, 2010, SOUVENIR: 44.

22. Acharya D, Malla S, Bhatta DR, Dumre SP. Multidrug Resistant Salmonella enterica serovar Typhi. J Nep Med Assooc 2009; 48 (174): 196-7. 